\title{
Embedded System Development Life Cycle- An Iterative Approach
}

\author{
Vishesh $\mathbf{S}^{1}$, Nagashree $\mathrm{KV}^{2}$, Rachana $\mathbf{B R}^{2}$, Poojashree $\mathbf{A P}^{2}$, Rupa ${ }^{3}$, Navamallika $\mathbf{N}^{4}$ \\ B.E, Department of Telecommunication Engineering, BNM Institute of Technology, Bangalore, India ${ }^{1}$ \\ Student, Department of Telecommunication Engineering, Dr.AIT, Bangalore, India ${ }^{2}$ \\ Student, Department of Information Science Engineering, BMSCE, Bangalore, India ${ }^{3}$ \\ Student, Department of Telecommunication Engineering, BMSCE, Bangalore, India ${ }^{4}$
}

\begin{abstract}
The Embedded System Product Development Life Cycle consist of different phases - Requirement analysis, Feasibility analysis, Design \& Implementation, Integration \& Testing, product release \& Marketing and Operations, Maintenance \& Upgrade. In the Embedded System Development Life Cycle there is a partition of responsibility or duties between Hardware development and Software development team. They work in parallel and in harmony. They unite or integrate after the design stage of Embedded System Development Life Cycle. Testing/ debugging needs to be done to make the product an instant hit/ free of bugs. We carryout functional testing, performance testing, security testing, usability testing, compatibility testing and recoverability testing. In this paper we will be dealing in detail, the tail stages of embedded system development life cycle. We consider the product that we have designed and carryout numerous iterations in these blocks to make the product more acceptable in the market based on various criticisms by the user, at the market place, seller etc.... The Embedded system development life cycle allows the vendor or manufacturer to introspect on various aspects, considerations, reviews and facets; hence, it is a flexible model and also reduces the cost, time to market and complexities.
\end{abstract}

Keywords: Embedded System Product Development Life Cycle, Requirement analysis, Feasibility analysis, Design \& Implementation, Integration \& Testing, product release \& Marketing, Operations, Maintenance \& Upgrade, functional testing, performance testing, security testing, usability testing, compatibility testing and recoverability testing, flexible model, cost, time to market and complexities.

\section{INTRODUCTION}

Embedded system development lifecycle consists of the following phases [1]

- Requirement analysis- Defining the requirements in abstract before going about with the product development.

- Feasibility analysis- Feasibility analysis is carried out before starting the Design and Implementation stage. There are various types of feasibility analysis- organizational feasibility, economic feasibility, HR and technical feasibility. After this the project is split into Hardware and Software design carried out parallelly.

- Design and implementation- Hardware and Software development is done simultaneously and in co-ordination.

- Integration and testing- here the software and hardware counterparts integrate.

- Product release and marketing.

- Operations, maintenance and upgrade.

\section{INTEGRATION AND TESTING}

Inegration and testing is a separate stage in the embedded system lifecycle. At this phase the Hardware design and Software designs domains are integrated, which were spilt after the feasibility analysis phase. It includes bringing the developed Hardware and the respective Software together and now the Software is called the embedded software. Testing is an organized process to verify the behaviour, performance and reliability of a device or system against designed specifications. Following are the types of testing that can be carried out.

- $\quad$ Functional testing.

- $\quad$ Performance testing

- $\quad$ Security testing

- Usability testing

- $\quad$ Compatibility testing

- Recoverability testing. 
Figure 1 shows the bottom phases/end phases of an embedded system development lifecycle.

\section{OPERATION, MAINTENANCE AND UPDATE}

After the Integration and Testing phase the embedded system is error or fault free and doesn't contain any bugs if proper debugging procedure is carried out. Now the product is ready to be launched into the market and rigorous marketing is done. Product reviews and feedback is collected and self-assessment of the product is carried out parallelly. Any small changes in the software or firmware is rectified in the form of updates and any changes to be brought about in the product, product re-release is carried out. Once the product is launched in the market operations and maintenance of various services which come along with the product needs to be carried out.

\section{BLOCK DIAGRAM AND METHODOLOGY}

In this paper we are developing a $\mathrm{CO}$ gas [2] detection system. Figure 2 shows different parts of $\mathrm{CO}$ gas detection embedded system. It is divided into

- Sensing unit

- Processing unit

- Connectivity unit

- Display unit

\section{A. Sensing unit}

Sensing unit consists of a sensor, multiple sensors or an array of similar or dissimilar sensors used to detect or respond to a single stimulus or stimuli. There are various parameters to be considered while choosing a sensor or type of sensor. They are Accuracy, Precision, Repeatability, Reproducibility, Stability, Error factor, Response time, Resolution, Noise, Selectivity, Linearity, Environmental compatibility etc... [3].Following are the types of sensors that are available.

\section{- $\quad$ Resistive sensors}

Resistive sensors can convert many physical parameters in our environment into a resistance that varies with temperature, light, pressure, moisture, chemical composition, sound or other inputs. The variable resistance will then change the voltage or current in a circuit, which can be further manipulated in an electrical system to produce desired output. We are using MQ7 resistive sensor [4] to detect the concentration of CO in ppm or \% vol in the environment or from a particular source. The chemical composition of the MQ7 sensor is as shown in table 1.

The Resistive MQ7 sensor works on the principle of ohm's law.

i.e.; $\mathrm{V}=\mathrm{IR} \quad(1)$

where, $V \propto I$

when $\mathrm{R}$ is a constant at constant temperature and when physical properties of the material remain unchanged.

\section{- $\quad$ Capacitive sensors}

A capacitive sensor converts a change in the position or properties of the dielectric material into an electrical signal. Any variations in any of the following parameters:

i. $\quad$ Distance (d)

ii. $\quad$ Area of capacitive plates (A)

iii. Dielectric constant $\left(\varepsilon_{\mathrm{r}}\right)$

$$
\text { in } \mathrm{C}=\mathrm{f}\left(\mathrm{d}, \mathrm{A}, \varepsilon_{\mathrm{r}}\right)
$$

leads to the change in the capacitance and further leads to change in the electrical signal and a particular output value in accordance with the stimulus/ stimuli.

\section{- $\quad$ Optical sensors}

There are various techniques used to detect various gases using the optical principle.

1. Optical absorption- Many of the most important optical gas sensing techniques exploit absorption. This is because many combustible and toxic gases have strong fundamental absorption bands in the $2-5 \mu \mathrm{m}$ region of the spectrum [5].

$\mathrm{CH}_{4}=3.3 \mu \mathrm{m}$

$\mathrm{H}_{2} \mathrm{~S}=2.7 \mu \mathrm{m}$

$\mathrm{CO}_{2}=4.2 \mu \mathrm{m}$

$\mathrm{CO}=4.6 \mu \mathrm{m}$

$\mathrm{NH}_{3}=2.3 \mu \mathrm{m}$ 
Absorption is characterised by Beer-Lambert's gas absorption law given by

$\mathrm{I}(\lambda)=$ Intensity of light at wavelength $\lambda$

$$
\mathrm{I}(\lambda)=\mathrm{I}_{0}(\lambda) \exp -[\mathrm{L} \sigma(\lambda) \mathrm{C}]
$$

$\mathrm{L}=$ gas layer thickness

$\mathrm{I}_{0}(\lambda)=$ initial intensity of the transmitted light at wavelength $\lambda$

$\sigma(\lambda)=$ Gas absorption cross-section at $\lambda$

$\mathrm{C}=$ Gas concentration

$$
\mathrm{C}=\log \left[\mathrm{I}_{0}(\lambda) / \mathrm{I}(\lambda)\right] /[\sigma(\lambda) \mathrm{L}]
$$

2. DIAL systems- A high power, pulsed LASER beam modulated at two wavelengths - one which is absorbed by the target gas and other which is not. The target gas is filled in a gas chamber at ambient temperature for sensing and intensity of LASER beam obtained at the detector gives the gas concentration of that target gas.

\section{B. Microcontroller}

Following are the parameters to be considered while choosing a microcontroller

- RAM

- $\mathrm{I} / \mathrm{O}$ ports (digital or analog)

- Processing speed

- ROM

- $\quad$ Type of EEPROM used

- Microcontroller pipelining architecture.

\section{Output device and connectivity}

- $\quad$ Option 1- PC or laptop (via Bluetooth or USB)

- $\quad$ Option 2- IoT or cloud (via Wi-Fi)

- $\quad$ Option3- Third party application installed in smartphone (via Bluetooth or Wi-Fi)

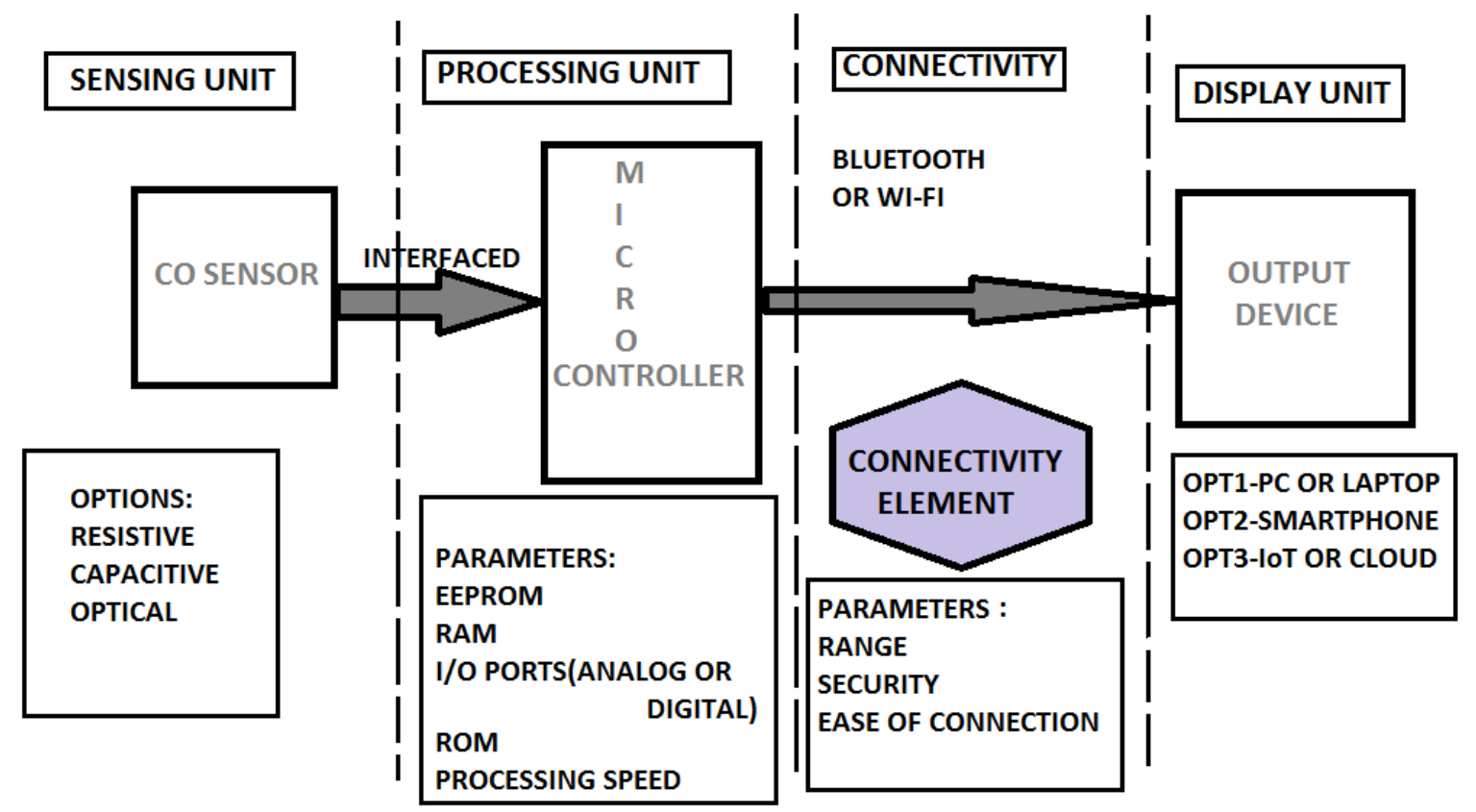

Figure 2 shows the block diagram of $\mathrm{CO}$ gas detection embedded system.

\section{CONCLUSIONS}

Before a product release in to the market it has to pass through various phases of testing- both Hardware and Software testing like functional testing, performance testing, security testing, usability testing, compatibility testing, recoverability testing etc. It is not the end because the user or stakeholder is the ultimate critic of a product and its service. Therefore, in this paper various parameters/alternatives to a product is thought about and the flexibility of the embedded system development lifecycle model enables the vendor to achieve the same with less effort than compared to traditional methods of product design. 


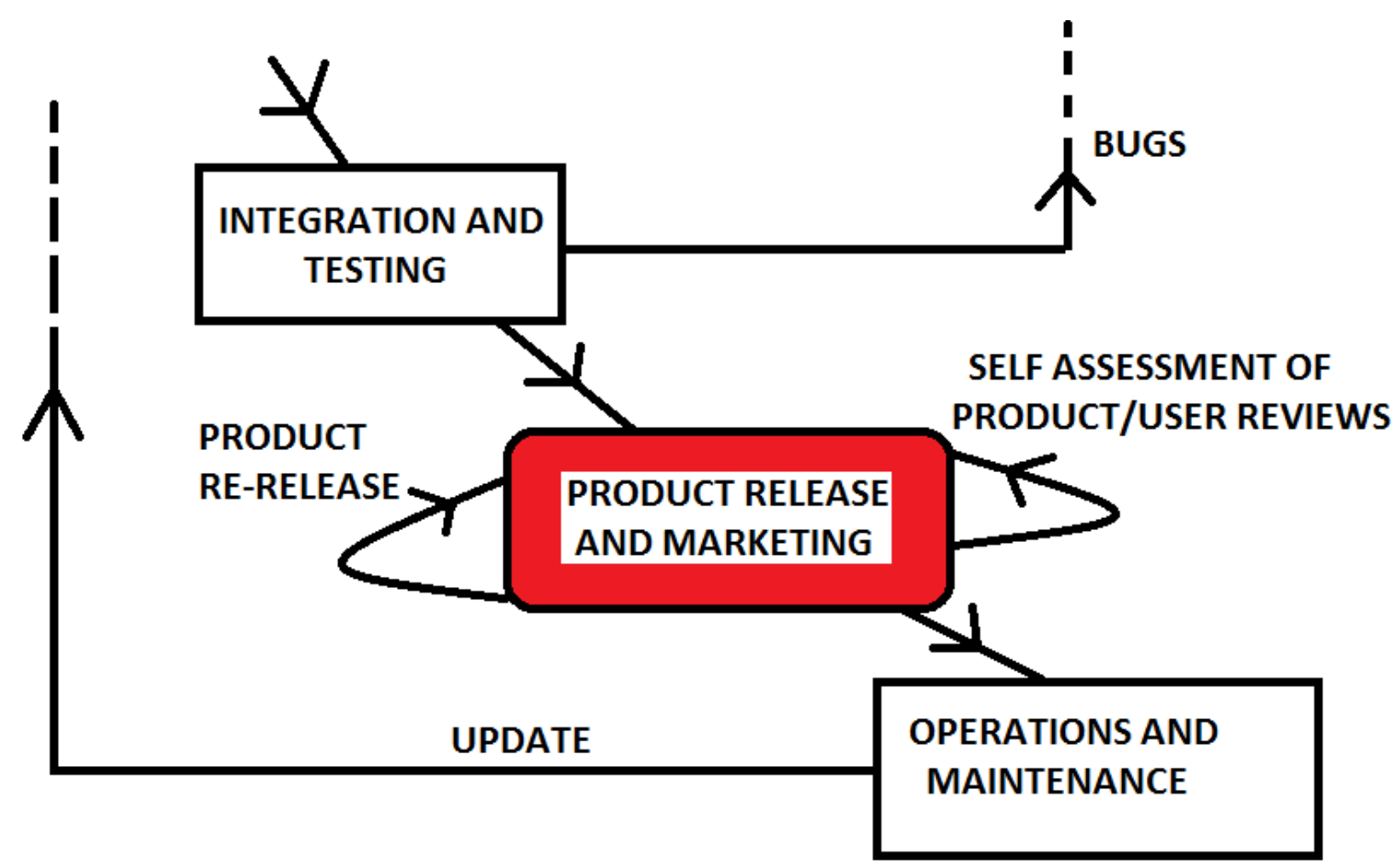

Figure 1 shows the bottom phases/end phases of an embedded system development lifecycle.

Table-1

\begin{tabular}{|l|l|l|}
\hline Sl no & Parts & Materials \\
\hline 1 & Gas sensing layer & $\mathrm{SnO}_{2}$ \\
\hline 2 & Electrode & $\mathrm{Au}$ \\
\hline 3 & Electrode line & $\mathrm{Pt}$ \\
\hline 4 & Heater coil & $\mathrm{Ni}-\mathrm{Cr}$ alloy \\
\hline 5 & Tubular ceramic & $\mathrm{Al}_{2} \mathrm{O}_{3}$ \\
\hline 6 & Anti-explosion network & Stainless steel \\
\hline 7 & Clamp ring & $\mathrm{Cu}$ platting Ni \\
\hline 8 & Resin base & Bakelite \\
\hline 9 & Tube pin & $\mathrm{Cu}$ platting Ni \\
\hline
\end{tabular}

\section{REFERENCES}

[1] "Android Application to Read and Record Data from Multiple Sensors" IJARCCE- DOI: 10.17148/IJARCCE.2017.6587

[2] Portable Low Cost Electronic Nose for Instant and Wireless Monitoring of Emission Levels of Vehicles Using Android Mobile Application Vishesh S1, Manu Srinath1, Karthik P Gubbi2, Shivu H N3, Prashanta3-DOI 10.17148/IJARCCE.2016.5931

[3] Practical Implementation of Real-time Sensing of Sensor Values using Android Application-1 Vishesh S1, Siri BC2 , Shivani YN2, Thanmayi BK2, Shweta Manjunath3, Sushmitha TS3-DOI10.17148/IJARCCE.2017.65117

[4] MQ-7 Manual- https://cdn.sparkfun.com/datasheets/Sensors/...MQ-7\%20Ver1.3\%20-\%20Manual.pdf

[5] Technology Roadmap: Optoelectronic Gas Sensors in the Petrochemicals, Gas and Water Industries:

R W Bogue, Robert Bogue \& Partners Issue: A.2 August 2006

\section{BIOGRAPHIES}

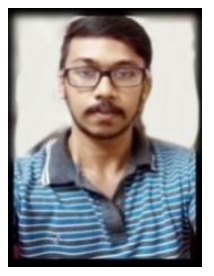

VISHESH $\mathbf{S}$ born on $13^{\text {th }}$ June 1992, hails from Bangalore (Karnataka) and has completed B.E in Telecommunication Engineering from VTU, Belgaum, Karnataka in 2015. He also worked as an intern under Dr Shivananju BN, Department of Instrumentation, IISc, Bangalore. His research interests include Embedded Systems, Wireless Communication and Medical Electronics. He is also the Founder and Managing Director of the company Konigtronics Private Limited. He has guided over a hundred students/lecturers/interns/professionals in their research works and projects. He is also the co-author of many International Research Papers. He is currently pursuing MBA. Presently Konigtronics Private Limited has extended its services in the field of Real Estate, Webpage Designing and Entrepreneurship. 


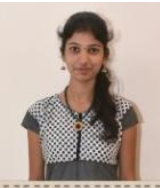

NAGASHREE
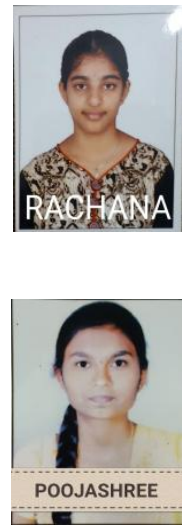

POOJASHREE AP is currently pursuing BE in Telecommunication Engineering at Dr.AIT, Bangalore. Her research interests include Embedded Systems and android coding.

RACHANA BR is currently pursuing BE in Telecommunication Engineering at Dr.AIT, Bangalore. Her research interests include Embedded Systems and android coding.

NAGASHREE KV is currently pursuing BE in Telecommunication Engineering at Dr.AIT, Bangalore. Her research interests include Embedded Systems and android coding.

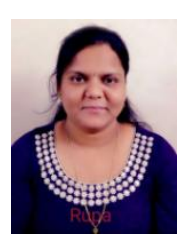

RUPA is currently pursuing BE in Information Science Engineering at BMSCE, Bangalore. Her research interests include Embedded Systems and android coding.

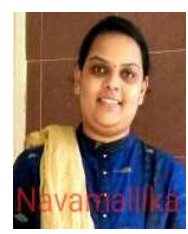

NAVAMALLIKA $\mathbf{N}$ is currently pursuing BE in Telecommunication Engineering at BMSCE, Bangalore. Her research interests include Embedded Systems and android coding. 